\title{
Article \\ 3-Hydroxy-5,6-epoxy- $\beta$-ionone Isolated from Invasive Harmful Brown Seaweed Sargassum Horneri Protects MH-S Mouse Lung Cells from Urban Particulate Matter-Induced Inflammation
}

\author{
K. K. Asanka Sanjeewa ${ }^{1,2}$ () , Hyun-Soo Kim ${ }^{2,3}$, Hyo-Geun Lee ${ }^{2}$, Thilina U. Jayawardena ${ }^{2}$ D , D. P. Nagahawatta ${ }^{2}$, \\ Hye-Won Yang ${ }^{2}$, Dhanushka Udayanga ${ }^{1}$, Jae-Il Kim ${ }^{4, *}$ (D) and You-Jin Jeon ${ }^{2,5, *(1)}$ \\ 1 Department of Biosystems Technology, Faculty of Technology, University of Sri Jayewardenepura, Pitipana, \\ Homagama 10206, Sri Lanka; asankasanjeewa@sjp.ac.lk (K.K.A.S.); dudayanga@sjp.ac.lk (D.U.) \\ 2 Department of Marine Life Science, School of Marine Biomedical Sciences, Jeju National University, \\ Jeju 63243, Korea; gustn783@naver.com (H.-S.K.); hyogeunlee92@gmail.com (H.-G.L.); \\ tujayawardena@jejunu.ac.kr (T.U.J.); pramuditha1992@jejunu.ac.kr (D.P.N.); koty221@naver.com (H.-W.Y.) \\ 3 Department of Applied Research, National Marine Biodiversity Institute of Korea, Seocheon 325902, Korea \\ 4 Department of Food Science \& Nutrition, Pukyong National University, Yongso-ro, 45, Busan 608737, Korea \\ 5 Marine Science Institute, Jeju National University, Jeju 63333, Korea \\ * $\quad$ Correspondence: jikim@pknu.ac.kr (J.-I.K.); youjinj@jejunu.ac.kr (Y.-J.J.); Tel.: +82-51-629-5849 (J.-I.K.); \\ +82-64-754-3475 (Y.-J.J.)
}

check for

updates

Citation: Sanjeewa, K.K.A.; Kim, H.-S.; Lee, H.-G.; Jayawardena, T.U.; Nagahawatta, D.P.; Yang, H.-W.; Udayanga, D.; Kim, J.-I.; Jeon, Y.-J. 3-Hydroxy-5,6-epoxy- $\beta$-ionone Isolated from Invasive Harmful Brown Seaweed Sargassum Horneri Protects MH-S Mouse Lung Cells from Urban Particulate MatterInduced Inflammation. Appl. Sci. 2021, 11, 10929. https://doi.org/ 10.3390/app112210929

Academic Editor: Alessio Adamiano

Received: 24 September 2021 Accepted: 16 November 2021 Published: 19 November 2021

Publisher's Note: MDPI stays neutral with regard to jurisdictional claims in published maps and institutional affiliations.

Copyright: (c) 2021 by the authors Licensee MDPI, Basel, Switzerland. This article is an open access article distributed under the terms and conditions of the Creative Commons Attribution (CC BY) license (https:/ / creativecommons.org/licenses/by/ $4.0 /)$.
Featured Application: Functional foods and nutraceuticals.

Abstract: Air pollution is a process that mixes pollutants into the atmosphere, which is potentially harmful to humans and causes negative impacts on the surrounding environment (biotic and abiotic). The negative health effects associated with air pollution have been reported from both indoor and outdoor environments. Specifically, dust storms originating in Chinese and Mongolian desert areas introduce significant amounts of particulate matter (PM) to the Korean atmosphere. Previously, several studies reported that urban PM (UPM) is a potential agent that causes inflammation in the lungs by altering multiple signal transduction pathways; therefore, screening and identification of anti-inflammatory compounds against UPM-induced inflammation is an urgent requirement. In the present study, we attempted to study the anti-inflammatory properties of 3-Hydroxy-5,6-epoxy- $\beta$ ionone (HEBI), a pure compound isolated from invasive brown seaweed, Sargassum horneri (brown edible seaweed), against UPM-stimulated lung macrophages (MH-S). Anti-inflammatory parameters of HEBI were evaluated using Western blots, ELISA, RT-qPCR, and MTT assays. According to the results, HEBI at concentrations between 31.3 and $125 \mu \mathrm{g} / \mathrm{mL}$ reduced UPM-induced NO, PGE2, and pro-inflammatory cytokine production via blocking the downstream signal transduction of NF- $\mathrm{kB}$ and MAPKs. Specifically, HEBI down-regulated the mRNA expression levels of Toll-like receptors 2 and 4, which are well-known NF- $\mathrm{kB}$ and MAPKs stimulators. Taken together, HEBI is a potential candidate to develop functional foods and active ingredients in cosmeceuticals because of its profound effects against UPM-induced inflammation in MH-S macrophages.

Keywords: lung macrophages; inflammation; oxidative stress; Sargassum horneri; particulate matter

\section{Introduction}

Air pollution is a process of mixing pollutants into the atmosphere, which are potentially harmful to humans and cause negative impacts on the surrounding environment (biotic and abiotic). Due to the high exposure risk, even at the low concentrations of fine dust, air pollution is a major health threat to human society [1]. Recently, several studies reported that elevated levels of particulate matter (PM) cause a reduced life expectancy of humans via increasing serious health complications [2]. Specifically, urban particulate matter (UPM) is one of the major sources of air pollution and directly affects the normal 
functions of the respiratory system, skin, and digestive tract. The sand storms originated in Mongolia and China's extensive arid and semiarid highlands carry a large amount of particulate matter to East-Asian countries such as South Korea and Japan [3]. In addition, coal-burning power plants, petroleum vehicles, and other industrial operations such as construction work also increase UPM concentration in the East-Asia region [4]. Studies have demonstrated that UPM can increase cancer cell development in the lungs [5].

Alveolar macrophages, such as MH-S, stay in the lower respiratory tract while phagocyte UPM particles reach the lower respiratory tract. Based on the particle size and heavy metal composition, UPM-exposed macrophages initiate inflammatory responses [6]. According to the previous studies, UPM act as inflammatory stimuli on macrophages. Recently, several studies reported that UPM could act as inflammatory stimuli in macrophages via stimulating inflammation-related signal cascades. The endotoxins presented in UPM particles were found to up-regulate the toll-like receptor (TLR)-4 dependent inflammatory responses via up-regulating pro-inflammatory cytokine secretion from $\mathrm{MH}-\mathrm{S}$ murine lung macrophages. Moreover, PMs moved to the lower respiratory tract phagocytes via macrophages and then were removed by lysosome activation. As a result, the macrophage population in the lungs decreased, which further reduced the immunity in UPM-exposed lungs [7].

Nuclear factor kappa-light-chain-enhancer of activated B cells (NF- $\mathrm{kB}$ ) has been a key mediator in inflammatory diseases. The activation of NF- $\mathrm{kB}$ is stimulated by factors such as LPS, viral infection, inflammatory cytokines (tumor necrosis factor-alpha and $r$ interleukins), and UV irradiation [8]. The activation and translocation of NF-KB proteins (p50 and p65) are strictly controlled by the inhibitor protein called IкB. Phosphorylation and subsequent degradation of I $\kappa B$ allow the activation and mobilization of NF- $\kappa B$ to the

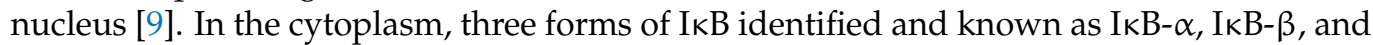
I $\mathrm{K} B-\varepsilon$. Among those, only IкB- $\alpha$ binds to p50 heterodimer and p50-p65 homodimer. After being translocated into the nucleus, NF- $\mathrm{kB}$ dimers bind to its target DNA elements and then stimulate the transcription of genes responsible for inflammation [8-10]. On the other hand, mitogen-activated protein kinases (MAPK) are an evolutionarily preserved family of enzymes capable of forming an integrated network required to complete important cell functions such as apoptosis, cell differentiation, and cell proliferation [11]. ERK1/2, JNK, and p38 are three known MAPKs involved in inflammatory gene regulation. To date, it has been reported that the MAPK kinase (MKK)1 and MKK-2 are involved in activating ERK1/2, MKK3, MKK4, and MKK6 in p38 MAPK activation; MKK4 and MKK7 are involved in the activation of JNK [12]. Inflammatory stimuli such as bacteria, fungi, and dust activate macrophages through the receptors located in the cell membrane. Furthermore, the activation of the MAPK pathway up-regulates the production of tumor necrosis factor alpha (TNF- $\alpha$ ), Interleukin (IL)-6, IL-8, and IL-1 $\beta$; known bio-markers of chronic inflammatory symptoms [13]; therefore, the compounds that are capable of inhibiting or down-regulating NF-KB and MAPK-related proteins might have the potential to be developed as anti-inflammatory drugs.

Sargassum horneri (Fucales, Phaeophyceae) is an invasive brown seaweed, which abundantly grows in the subtidal zone as an annual species along with the coastal areas of Korea, Japan, and China [14]. From November to March S. horneri grows rapidly and reaches up to $7 \mathrm{~m}$ in length [15]. S. horneri is also rich in essential vitamins, amino acids, and polysaccharides. In addition, it has been considered a medicinal ingredient in traditional folk medicine for centuries in the East-Asia region [16,17]; however, S. horneri has been identified as an invasive brown seaweed species in coastal areas of Jeju island and southern coastlines of South Korea [18]. Previous studies have reported that the large amounts of biomass accumulated around the shallow coastal areas of South Korea negatively affected the aquaculture and fisheries industries in Korea [18,19]; thus, effective utilization methods are required to remove drifting biomass of $S$. horneri in a cost-effective method. As far as we understand, using $S$. horneri as an industrial level raw material is one possible approach to effectively controlling this seaweed; however, before we can achieve this, 
many research studies are required to determine the suitability of $S$. horneri as a functional ingredient for industrial applications. Furthermore, our previous studies demonstrated the protective effects of ethanolic extract separated from S. horneri against UPM-induced inflammatory responses using in vivo and in vitro models. According to our observations, S. horneri down-regulated the activation of the TLR-mediated downstream activation of MAPKs and NF- $\mathrm{B}$, and consequent inflammatory symptom development in murine models and lung macrophages [20,21]; however, the identification and characterization of the active compounds responsible for the aforementioned activities are important to formulate functional foods and nutraceuticals; therefore, we attempted to determine the anti-inflammatory mechanisms associated with 3-hydroxy-5,6-epoxy- $\beta$-ionone isolated from $S$. horneri against UPM-exposed mouse lung macrophages.

\section{Materials and Methods}

\subsection{Chemicals and Reagents}

UPM was acquired from the National Institute for Environmental Studies, Ibaraki, Japan. MH-S macrophages (ATCC ${ }^{\circledR}$ CRL-2019TM) were purchased from an American-Type Culture Collection, Manassas, VA, USA. RPMI-1640 was purchased from Life Technologies Corporation, Grand Island, NY, USA. Prostaglandin E2 (PGE $)$ Parameter ${ }^{\mathrm{TM}}$ and IL-1 $\beta$ ELISA assay kits were purchased from R\&D Systems Inc (Minneapolis, MN, USA). ELISA Kits for IL-6 and TNF- $\alpha$ were purchased from Becton, Dickinson and Company (BD Biosciences; San Jose, CA, USA). NE-PER ${ }^{\circledR}$ nuclear and cytoplasmic protein extraction kit was purchased from Thermo Scientific, Rockford, IL, USA. The primary and secondary antibodies used in this study were purchased from Cell Signalling Technology, Beverly, MA, USA. Rabbit polyclonal Inducible nitric oxide synthase (iNOS), Cyclooxygenase-2 (COX2), IкB- $\alpha, P$-IкB- $\alpha$, NF-kb p50, NF-kb p65, P-p50, P-p65, JNK, P-JNK, ERK42/44, $P$-ERK42/44, nucleolin, and $\beta$-actin.

\subsection{Purification and Isolation of HEBI from S. horneri}

First, S. horneri was extracted with $80 \%$ methanol at room temperature and then fractionated into hexane, chloroform, and ethyl acetate. Then, the chloroform fraction was further purified using high-performance centrifugal partition chromatography (HPCPC). The structure of 3-Hydroxy-5,6-epoxy- $\beta$-ionone (HEBI) is illustrated in Figure 1 . The isolated compound has several names in National Center for Biotechnology Information Support Center (NCBI) database and is also known as 3-Buten-2-one, 4-(4-hydroxy-2,2,6trimethyl-7-oxabicyclo[4.1.0]hept-1-yl)-. In addition, the PubChem CID of HEBI is 5371267. Additional details of the compounds are available at the following link. https:/ / pubchem. ncbi.nlm.nih.gov/compound/5371267\#section=Top, accessed on 12 November 2021. Detail methods and isolation procedures of HEBI were reported in Kim et al. (2021) and the same isolated HEBI sample batch was used for this study [22].

\subsection{Estimation of UPM}

The particle size distribution of UPM was determined according to the previously reported method by Sanjeewa et al. (2020).

\subsection{Cell Culture and Sample Treatment}

MH-S macrophages were cultured in RPMI-1640 medium supplemented with 10\% fetal bovine serum $(v / v)$ and $1 \%$ penicillin-streptomycin $(v / v)$ (Life Technologies Corporation, Grand Island, NY, USA). The cells were incubated under a humidified atmosphere of $5 \%$ $\mathrm{CO}_{2}$ at $37^{\circ} \mathrm{C}$. MH-S cells were sub-cultured within 2 days intervals. HEBI was dissolved in Dimethylsulfoxide and then diluted in RPMI to treat cells. UPM is directly dissolved in the RPMI medium to treat cells. For all studies, cells were cultured $1 \times 10^{5}$ cells $/ \mathrm{mL}$ density. 
a

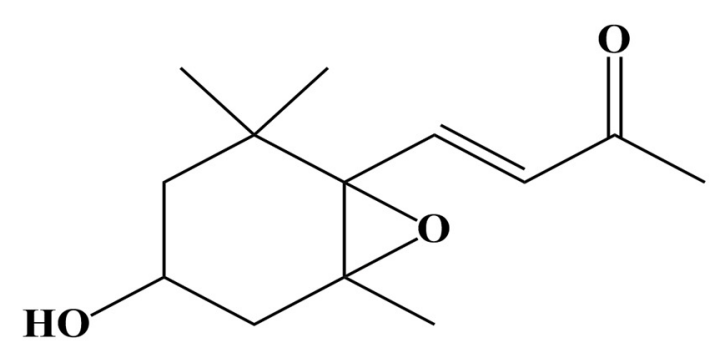

3-Hydroxy-5,6-epoxy- $\beta$-ionone b

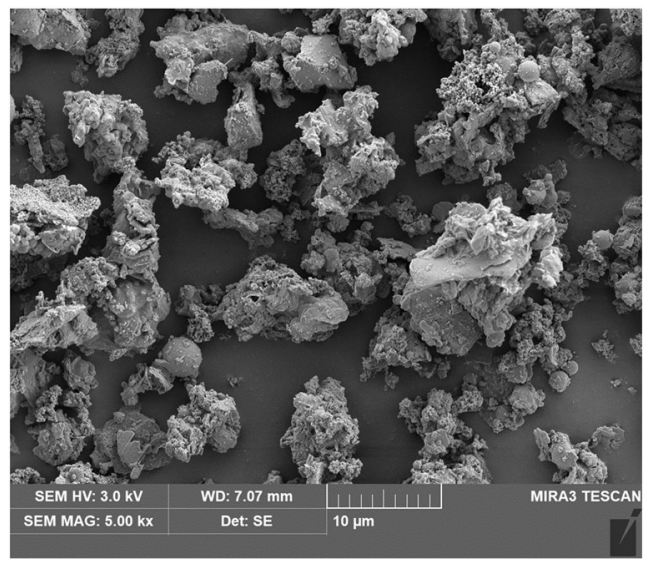

Figure 1. Chemical structure of 3-Hydroxy-5,6-epoxy- $\beta$-ionone (a) and scanning electron microscopic image of fine urban dust (b).

\subsection{3-(4,5-Dimethylthiazol-2-yl)-2,5-diphenyltetrazolium Bromide (MTT) Assay}

The cytotoxic effect of HEBI, UPM, and their blends on MH-S macrophages was determined with MTT assay. The MTT (Sigma-Aldrich Co St. Louis, MO, USA) assay was performed similarly to the previously modified method by Sanjeewa et al. (2017). MH-S cells were seeded into 24-well plates and incubated for $24 \mathrm{~h}$ at $37^{\circ} \mathrm{C}$. Then, the cells were exposed to different concentrations of HEBI $(15.6,31.3$, and $62.5 \mu \mathrm{g} / \mathrm{mL}), \mathrm{UPM}$ $(15.6,31.3,62.5$, and $125 \mu \mathrm{g} / \mathrm{mL})$, or their combinations for $24 \mathrm{~h}$. Then, $100 \mu \mathrm{L}$ of MTT solution $(2 \mathrm{mg} / \mathrm{mL})$ was added to each well, followed by incubation at $2 \mathrm{~h}$ at $37^{\circ} \mathrm{C}$. Then, the remaining medium was removed, the resultant formazan crystals were dissolved in dimethyl sulfoxide (Sigma-Aldrich Co., St. Louis, MO, USA), and color development was observed at $540 \mathrm{~nm}$. The color intensity at $540 \mathrm{~nm}$ in the untreated group is considered to represent $100 \%$ cell viability.

\subsection{Determination of NO Secretion Levels}

$\mathrm{NO}$ concentrations in MH-S culture supernatants were evaluated using a photometric analysis. Briefly, $450 \mu \mathrm{L}$ of MH-S cell suspensions were incubated on 24-well plates for $24 \mathrm{~h}$. Then, they were treated with $25 \mu \mathrm{L}$ of HEBI $(15.6-62.5 \mu \mathrm{g} / \mathrm{mL})$ to each well and incubated for $1 \mathrm{~h}$ at $37^{\circ} \mathrm{C}$. Then, $25 \mu \mathrm{L}$ of UPM $(31.3 \mathrm{mg} / \mathrm{mL}$ was dissolved in the RPMI1640) and added into each well, followed by incubation at $37^{\circ} \mathrm{C}$ for $24 \mathrm{~h}$. The culture supernatants were mixed with an equivalent volume of Griess reagent. After $10 \mathrm{~min}$ incubation, absorbance was noted at $540 \mathrm{~nm}$ [23].

\subsection{Determination of $P G E_{2}$ and Pro-Inflammatory Cytokine Secretion}

PGE $_{2}$, TNF- $\alpha$, IL- $1 \beta$, and IL- 6 in MH-S culture supernatants of UPM and HEBI cotreated MH-S macrophages were measured using specific ELISA kits according to the manufacturer's instructions.

\subsection{Western Blot Analysis}

MH-S cells were cultured and treated with HEBI and stimulated with UPM for $24 \mathrm{~h}$. Nuclear and cytoplasmic proteins were extracted using a commercial protein extraction kit with the manufacturer's instructions. The Western blots were performed according to the previously reported method (Sanjeewa et al., 2017). Briefly, cytosolic and nucleus proteins were extracted with a nuclear and cytoplasmic protein extraction. An equal amount of protein was electrophoresed in 10\% SDS-PAGE. Then, the separated proteins 
were transferred onto PVDF membranes. PVDF membranes were incubated with primary antibody (1:1000 dilution) in a cold room for $8 \mathrm{~h}$. The blots were washed two times with tween 20/Tris-buffered saline and incubated with HRP-conjugated rabbit IgG for $45 \mathrm{~min}$ (1:3000) at room temperature. The protein bands on PVDF membranes were detected by using an enhanced chemiluminescent substrate. Membranes were captured using a FUSION SOLO Vilber Lourmat system. Signal intensities of protein bands were determined by densitometry using ImageJ (version 1.4, Bethesda, MD, USA). The expression levels of each protein or their phosphorylation levels were normalized to their respective total forms or to $\beta$-actin or nucleolin using the ImageJ program [16].

\subsection{Quantitative RT-PCR}

Total RNA isolated from MH-S mouse lung macrophage cell cultures using a commercially available Tri-Reagent ${ }^{\mathrm{TM}}$ (Sigma-Aldrich, St. Louis, MO, USA) and performed qRT-PCR reactions using SYBR Green (TaKaRa, Shiga, Japan) superscript analyzed on a Thermal Cycler Dice-Real Time System (TaKaRa, Japan) RT-PCR Detection System using the primer sequences given in Table 1. The relative expression levels were calculated using the $2^{-\Delta \Delta C T}$ method [24]. The relative expression levels of tested genes are reported as the mean \pm standard deviation (SD) of the relative mRNA expression from at least 3 different trials. The two-tailed unpaired Students $t$-test was used to determine $p$ values.

Table 1. The sequences of the primers used to evaluate inflammation-related RNA expression levels.

\begin{tabular}{ccc}
\hline Gene & Primer & Sequence $\mathbf{( 5}^{\prime} \rightarrow \mathbf{3}^{\prime} \mathbf{)}$ \\
\hline \multirow{2}{*}{ GAPDH } & $\begin{array}{c}\text { Forward } \\
\text { Reverse }\end{array}$ & AAGGGTCATCATCTCTGCCC \\
& GTGATGGCATGGACTGTGGT \\
\hline \multirow{2}{*}{ iNOS } & $\begin{array}{c}\text { Forward } \\
\text { Reverse }\end{array}$ & ATGTCCGAAGCAAACATCAC \\
& TAATGTCCAGGAAGTAGGTG \\
\hline \multirow{2}{*}{ COX2 } & Forward & CAGCAAATCCTTGCTGTTCC \\
& Reverse & TGGGCAAAGAATGCAAACATC \\
\hline \multirow{2}{*}{ IL-1 $\beta$} & Forward & CAGGATGAGGACATGAGCACC \\
& Reverse & CTCTGCAGACTCAAACTCCAC \\
\hline \multirow{2}{*}{ IL-6 } & Forward & GTACTCCAGAAGACCAGAGG \\
\multirow{2}{*}{ TNF- $\alpha$} & Reverse & TGCTGGTGACAACCACGGCC \\
& Forward & TTGACCTCAGCGCTGAGTTG \\
\multirow{2}{*}{ TLR2 } & Reverse & CCTGTAGCCCACGTCGTAGC \\
\hline \multirow{2}{*}{ TLR4 } & Forward & CAGCTGGAGAACTCTGACCC \\
& Reverse & CAAAGAGCCTGAAGTGGGAG \\
\hline & Forward & CAACATCATCCAGGAAGGC \\
& Reverse & GAAGGCGATACAATTCCACC \\
\hline
\end{tabular}

\subsection{Statistical Analysis}

All results are expressed as the mean \pm standard error (SE) of three independent experiments. Statistical calculations were performed using repeated-measures ANOVA followed by Duncan's multiple range test (SPSS; V 20.0) or using Students $t$-test where appropriate (Microsoft Office Professional Plus 2019). $p<0.05$ and 0.01 were considered statistically significant.

\section{Results}

\subsection{Composition of UPM}

As shown in Figure 1b, UPM did not distribute equally and had different particle sizes and shapes. According to the scanning electron microscope image (SEM), a small amount of UPM had 10-15 $\mu$ m diameter, and a considerable amount of UPM had less than $3 \mu \mathrm{m}$ diameter. 


\subsection{Effect of UPM on Viability and NO Secretion of MH-S Macrophages}

To determine the cytotoxicity of UPM in MH-S lung macrophages, cells were incubated with four different concentrations prepared from UPM. As shown in Figure 2a, cell viability decreased with the increasing concentrations of UPM, which differed significantly from the control group after the $31.3 \mu \mathrm{g} / \mathrm{mL}$.

a

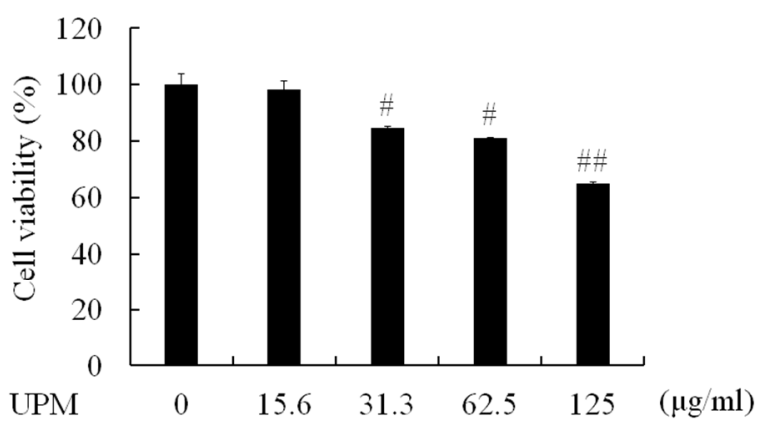

c

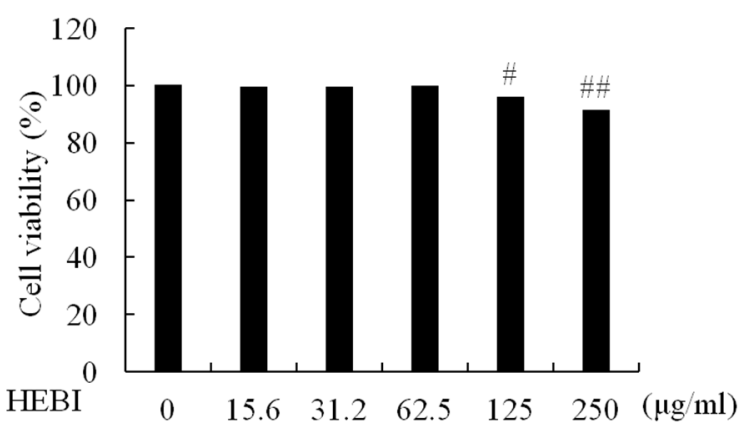

e

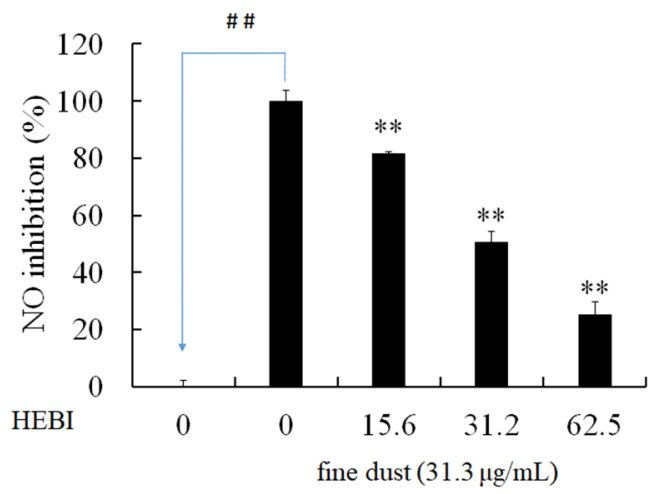

b

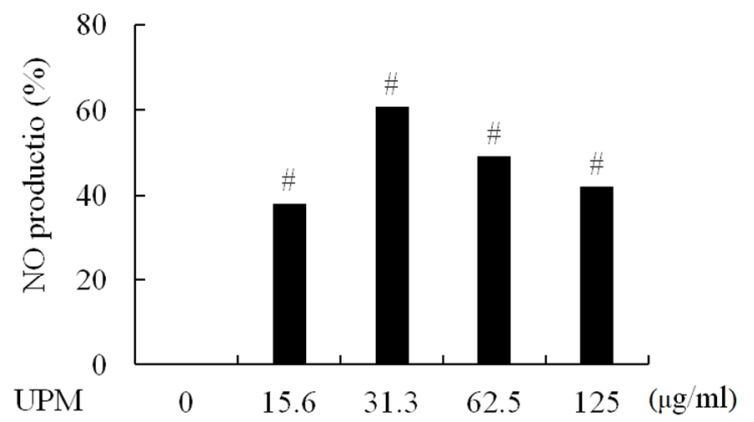

d

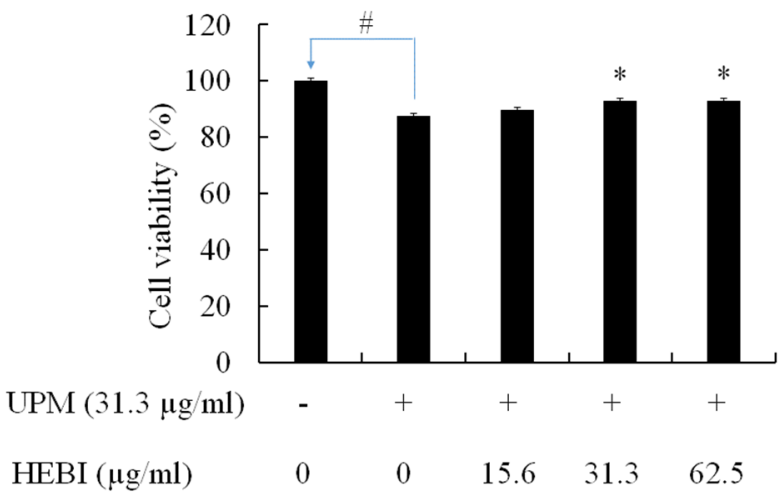

f

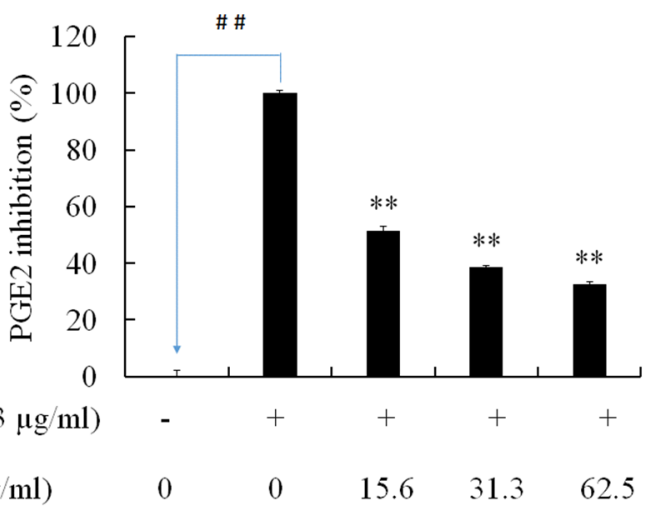

Figure 2. Protective effect of 3-hydroxy-5,6-epoxy- $\beta$-ionone (HEBI) against urban fine dust (UPM)-activated inflammatory responses in MH-S lung macrophages. UPM-induced toxicity (a) and NO production (b) in MH-S macrophages. MH-S macrophages were incubated with HEBI (c) for $24 \mathrm{~h}$ without UPM stimulation. Cytoprotective effect of (d), NO inhibition (e), and PGE 2 (f) in HEBI co-treated and UPM stimulated MH-S macrophages were compared using MTT, Geriss, and ELISA assays, respectively. Data are expressed as mean \pm S.D. from three independent experiments. ${ }^{*} p<0.05$ or ${ }^{* *} p<0.01$ compared with UPM-stimulated group and ${ }^{\#} p<0.05$ or $^{\# \#} p<0.01$ compared to control group. 
In parallel to the cell viability results, NO secretion increased with UPM concentrations up to $31.3 \mu \mathrm{g} / \mathrm{mL}$ and then declined (Figure $2 \mathrm{~b}$ ). The reduction of NO levels in concentrations higher than $31.3 \mu \mathrm{g} / \mathrm{mL}$ might be associated with reduced cell viability. Previously, several studies reported the exposure of macrophages to PM cause to induce chronic inflammatory responses and activate apoptosis signal cascades induce cell death in healthy tissues. With the electron microscope analysis, a considerable amount of UPM contained less than $2.5 \mu \mathrm{m}$ diameter PM. It has been reported that particles smaller than $2.5 \mu \mathrm{m}$ can easily go through the throat and nose to reach the alveolus [25]; thus, UPM can potentially induce adverse health consequences in the respiratory system via altering inflammatory signals. With these observations and previous evidence, we decided to use a $31.3 \mu \mathrm{g} / \mathrm{mL}$ concentration of UPM for further studies.

\subsection{Effect of HEBI on the Viability of MH-S Macrophages}

The colorimetric MTT assay was performed to select optimal concentrations for consequent studies. According to the results, the concentrations between 15.6 to $62.5 \mu \mathrm{g} / \mathrm{mL}$ did not show a considerable cytotoxic effect on MH-S macrophages (Figure 2c); however, concentrations higher than $125 \mu \mathrm{g} / \mathrm{mL}$ significantly reduced MH-S cell viability; therefore, concentrations below $125 \mu \mathrm{g} / \mathrm{mL}$ were used for the subsequent studies.

\subsection{HEBI Down-Regulated UPM-Induced Cell Death, NO, and PGE 2 Release in MH-S Cells}

In the present study, NO inhibitory levels and cytoprotective effects of UPM-exposed macrophages with the presence of HEBI were recorded. According to the results, UPMexposed MH-S cells had significantly low cell viability than the control group (Figure 2d) and showed up-regulated NO secretion (Figure 2e); however, pre-treatment of HEBI reduced the cell viability reduction percentage and NO production levels observed in UPM-exposed macrophages. In addition to NO secretion, several studies reported that the exposure of macrophages to PM resulted in the up-regulated secretion of pro-inflammatory cytokines and $\mathrm{PGE}_{2}$ [26]. Figure $2 \mathrm{f}$ shows that the levels of $\mathrm{PGE}_{2}$ in the culture supernatants collected from MH-S were evaluated using a commercial ELISA kit. As expected, UPMstimulated MH-S culture supernatants had significantly high $\mathrm{PGE}_{2}$ secretion compared to the unstimulated control; however, HEBI-treated macrophages showed a weakened $\mathrm{PGE}_{2}$ secretion after UPM-stimulation. These data confirmed the specific role of HEBI in NO and $\mathrm{PGE}_{2}$ secretion in UPM-activated lung macrophages.

\subsection{HEBI Down-Regulated UPM-Induced iNOS and COX2 Production}

As the next part of our study, the expression levels of iNOS and COX2 in UPMstimulated MH-S macrophages and HEBI co-treated cells were determined using Western blots. According to the results shown in Figure 3a, UPM triggers iNOS and COX2 (mRNA and proteins) production from MH-S cells (Figure 3a,b). Particularly, HEBI significantly reduced the expression of iNOS (Figure 3c) and COX2 (Figure 3d) at 15.6-62.5 $\mu \mathrm{g} / \mathrm{mL}$ compared with the UPM-treated alone group.

\subsection{HEBI Down-Regulated UPM-Stimulated Pro-Inflammatory Cytokine Secretion}

As the next part of the study, we determined the pro-inflammatory cytokine secretion levels of UPM-exposed MH-S cells after treating them with HEBI (Figure 4). ELISA assays and RT-qPCR were used to evaluate pro-inflammatory cytokines levels (IL- $1 \beta$; Figure $4 \mathrm{a}-\mathrm{d}$, IL-6; Figure $4 \mathrm{~b}-\mathrm{e}$, and TNF- $\alpha$; Figure 4c-f) in UPM-exposed MH-S cells. According to protein and mRNA expression results, HEBI inhibited the elevated pro-inflammatory cytokine secretion in UPM-stimulated MH-S cells. Specifically, the levels of IL-6 ( $\sim 8$ folds) and TNF- $\alpha$ ( $\sim 35$ folds) mRNA levels were up-regulated after being exposed to UPM (Figure $4 \mathrm{e}, \mathrm{f})$. 
a

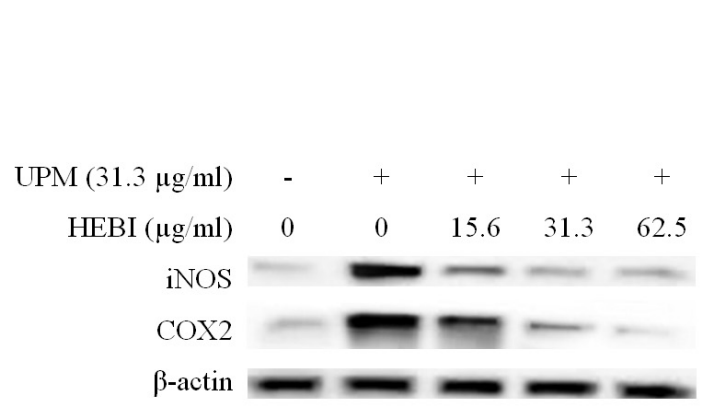

c

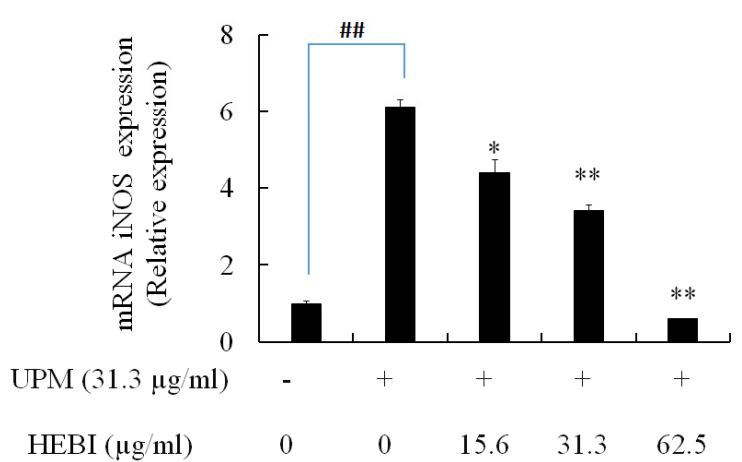

b

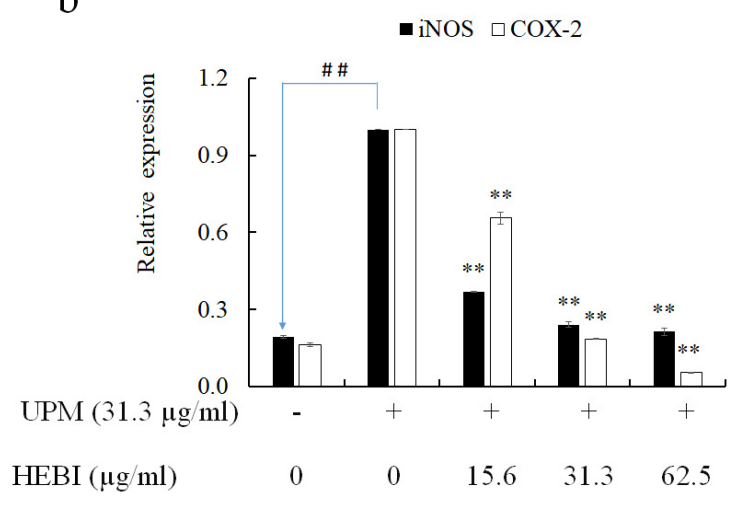

d

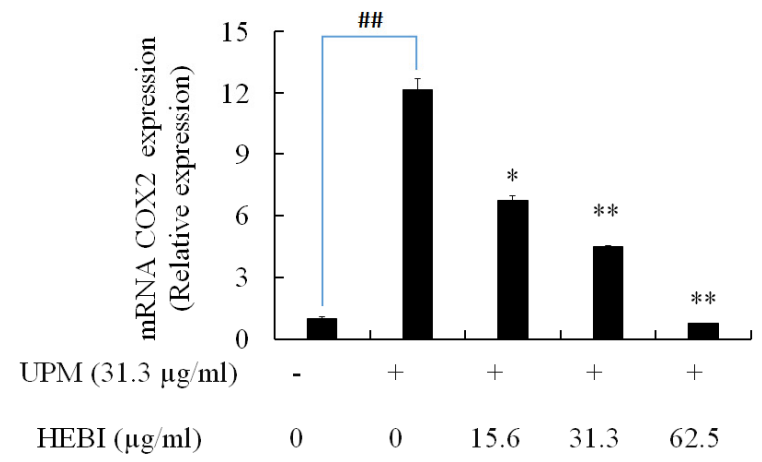

Figure 3. 3-Hydroxy-5,6-epoxy- $\beta$-ionone (HEBI) inhibits urban fine dust (UPM)-induced iNOS and COX2 in MH-S cells. MH-S murine lung macrophages were exposed to different concentrations of HEBI for $1 \mathrm{~h}$ and then stimulated with UPM $(31.3 \mu \mathrm{g} / \mathrm{mL})$ for $24 \mathrm{~h}$. The total lysates of proteins were analyzed by Western blots (a) and quantified using ImageJ software (b). The relative mRNA expressions of $i N O S$ (c) and COX2 (d) were determined by RT-qPCR. Data are expressed as mean \pm S.D. $(n=3)$. ${ }^{*} p<0.05$ or ${ }^{* *} p<0.01$ compared with UPM-stimulated group and ${ }^{\# \#} p<0.01$ compared to control group.

\subsection{Inhibitory Effect of HEBI against UPM-Induced TLR Activations (RT-qPCR)}

In the present study, we attempted to determine the relative gene expression levels of TLR 2 (Figure 5a) and TLR 4 (Figure 5b) using RT-qPCR to identify the effect of UPM on TLRs activation. According to the results, TLR 2 and TLR4 expression levels were significantly increased in response to UPM; however, HEBI dose-dependently reduced the expression levels of TLR 2 and 4.

\subsection{Suppressive Effect of HEBI in UPM-Induced NF-кB Activation}

The phosphorylation levels of IKB- $\alpha$ (Figure 6a), p50, and p65 were compared using Western blot analysis. According to the Western blot analysis, UPM increased the phosphorylation levels of I $\kappa$ B- $\alpha$ compared to the unstimulated cells (Figure $6 \mathrm{~b}$ ). In parallel to $P$-IкB- $\alpha$, the cytosolic $P$-p50 and $P$-p65 were significantly increased in the UPM-exposed groups (Figure 6c); however, the elevated phosphorylation levels of the aforementioned proteins were dose-dependently decreased with the treatment of HEBI (Figure 6d). These results suggest that the isolated compound has an inhibitory effect on the phosphorylation of IKB- $\alpha$, inhibiting the phosphorylation of p50 and p65 in the cytosol. Besides the cytosolic NF- $\mathrm{KB}$ inhibition, we attempted to evaluate NF- $\mathrm{kB}$ translocation levels in the nucleus using Western blot analysis (Figure 6e). In response to UPM, levels of p50 and p65 were dramatically increased in UPM treated MH-S cells (Figure 6f); however, co-treatment of HEBI before UPM stimulation decreased the elevated p50 and p65 in the nucleus observed in the UPM-stimulated MH-S macrophages. 
a

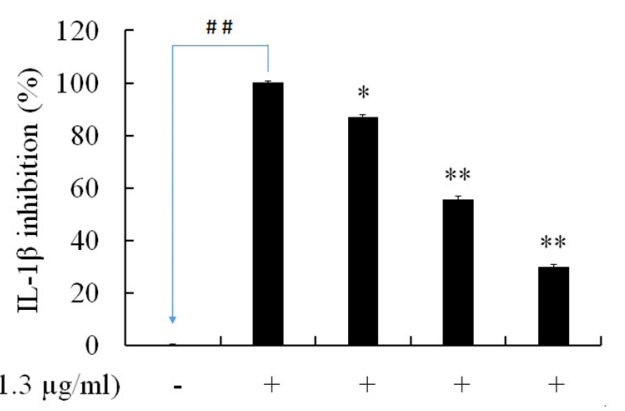

$\begin{array}{llllll}\mathrm{HEBI}(\mu \mathrm{g} / \mathrm{ml}) & 0 & 0 & 15.6 & 31.3 & 62.5\end{array}$

b

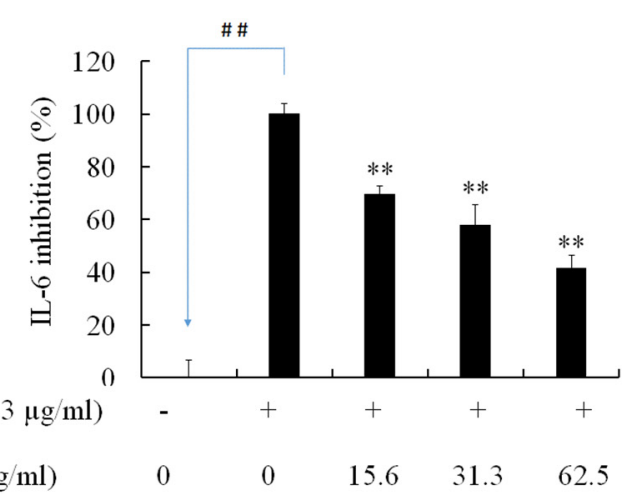

c

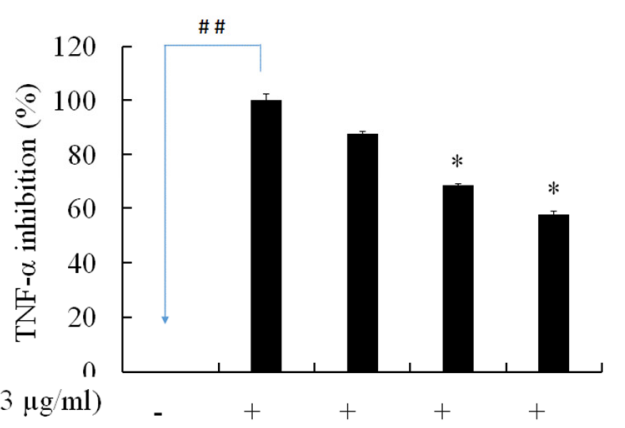

HEBI $(\mu \mathrm{g} / \mathrm{ml})$ d
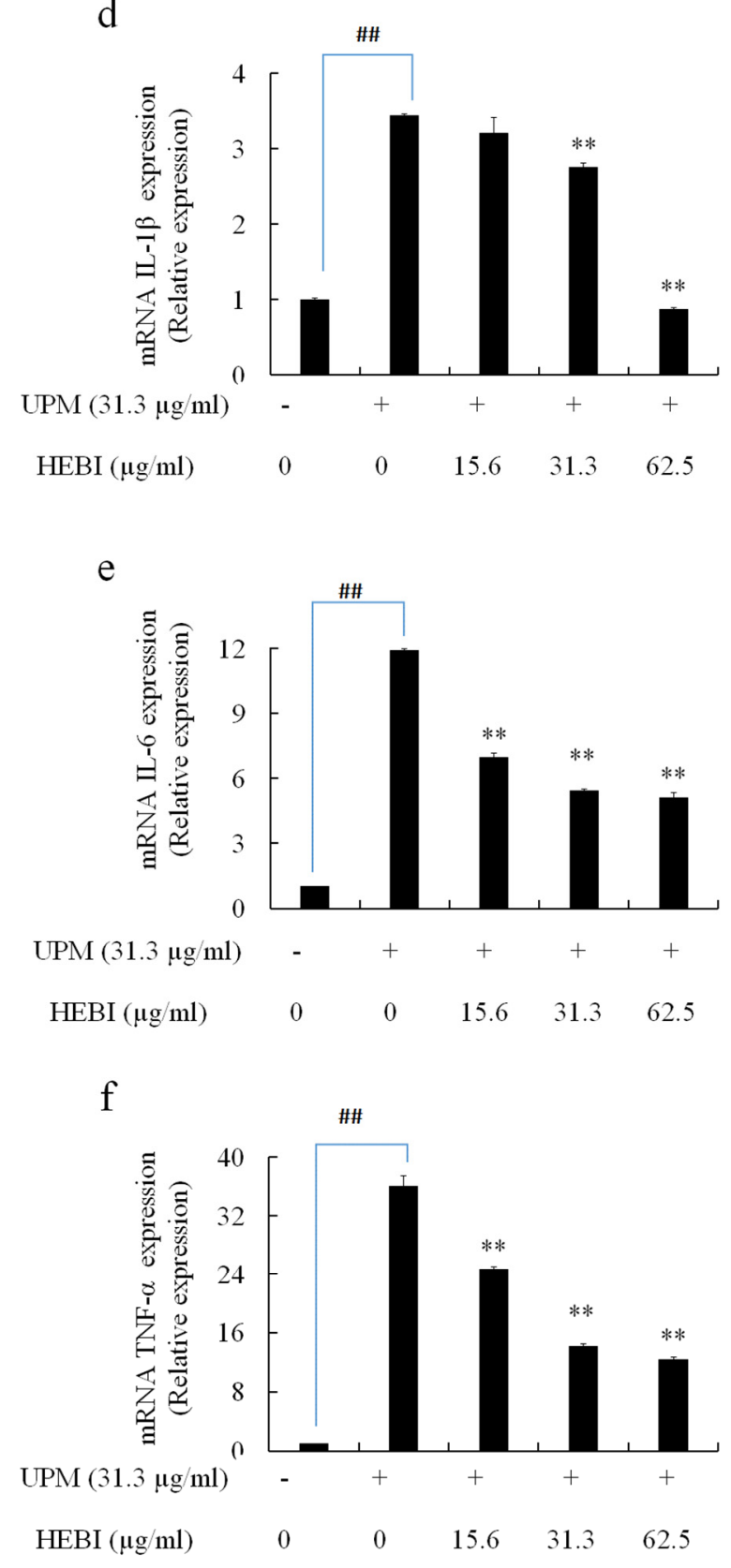

Figure 4. Effect of 3-hydroxy-5,6-epoxy- $\beta$-ionone (HEBI) against urban fine dust (UPM)-induced pro-inflammatory cytokine production in MH-S macrophages. MH-S macrophages were exposed to HEBI (15.6-62.5 $\mu \mathrm{g} / \mathrm{mL})$ for $1 \mathrm{~h}$. The protein levels of IL-1 $\beta$ (a), IL-6 (b), and TNF- $\alpha$ (c) in the culture media were detected by ELISA after UPM $(31.3 \mu \mathrm{g} / \mathrm{mL})$ stimulated for $24 \mathrm{~h}$. The relative mRNA expression levels of IL-1 $\beta$ (d), IL-6 (e), and TNF- $\alpha(\mathbf{f})$ were detected with RT-q PCR followed by UPM treatment for $24 \mathrm{~h}$. Data are expressed as mean \pm S.D. $(n=3){ }^{*} p<0.05$ or ${ }^{* *} p<0.01$ compared with UPM-stimulated group and ${ }^{\#} p<0.01$ compared to control group. 


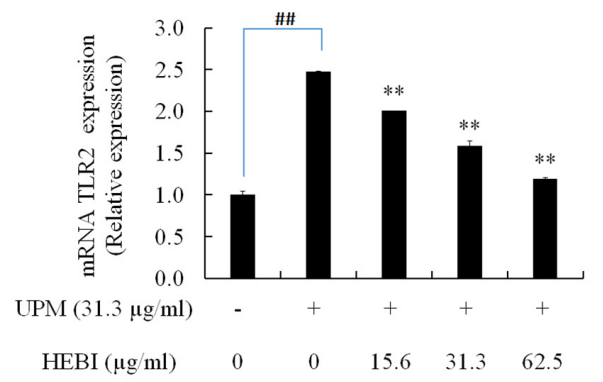

b

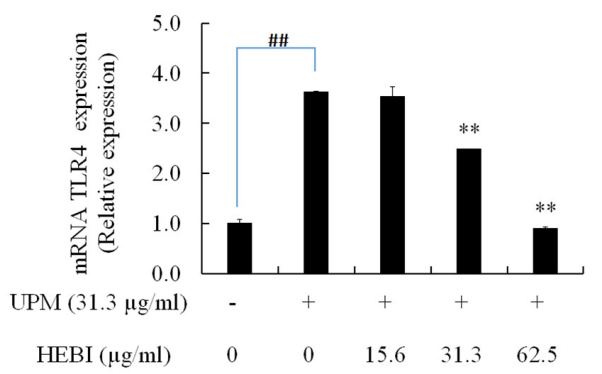

Figure 5. Effect of 3-Hydroxy-5,6-epoxy- $\beta$-ionone (HEBI) against urban fine dust (UPM)-induced TLR2 (a) and TRL4 (b) expressions in MH-S macrophages. MH-S macrophages were exposed to different concentrations of HEBI for $1 \mathrm{~h}$. The mRNA transcriptional activities of TLR2 and TLR4 were detected with RT-q PCR followed by UPM induced for $24 \mathrm{~h}$. Data are expressed as mean \pm S.D. $(n=3)$. ${ }^{* *} p<0.01$ compared with UPM-stimulated group and ${ }^{\# \#} p<0.01$ compared to control group.

a

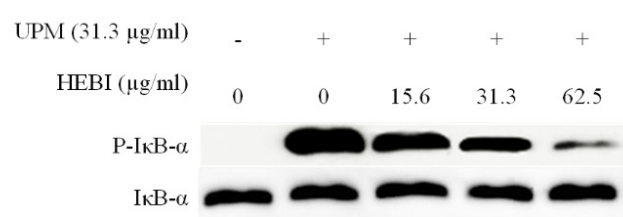

c

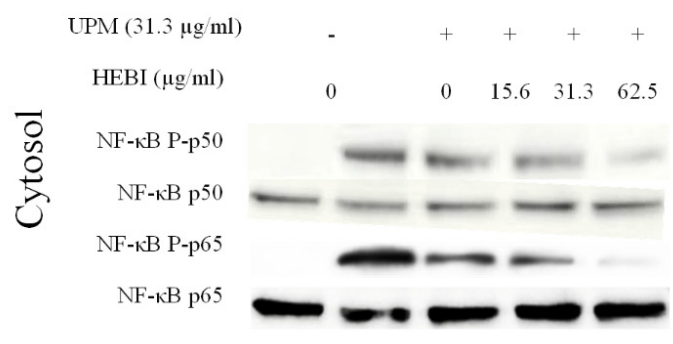

e

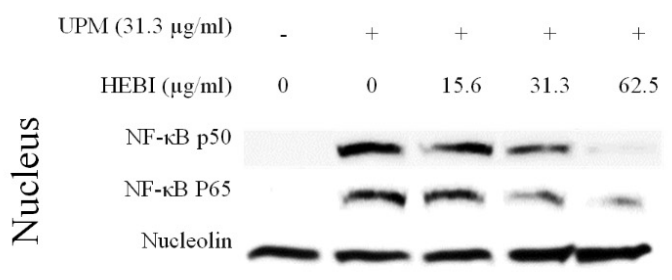

b

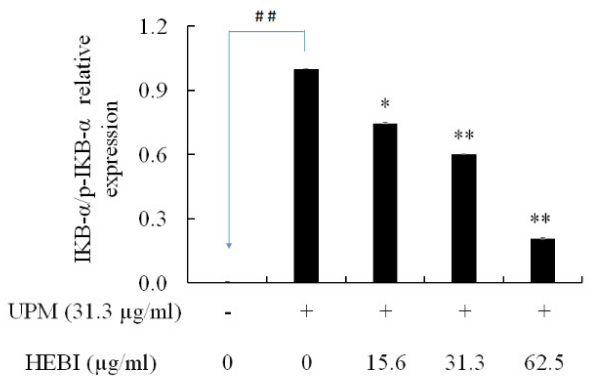

d

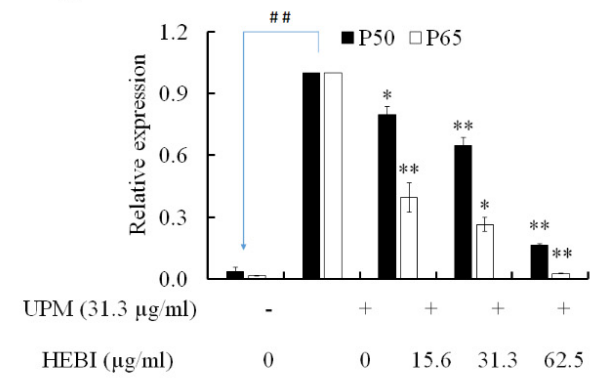

f

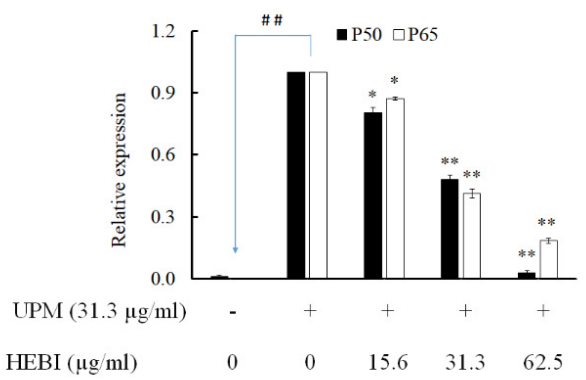

Figure 6. Effect of 3-hydroxy-5,6-epoxy- $\beta$-ionone (HEBI) against urban fine dust (UPM)-induced NF- $\mathrm{B}$ phosphorylation in MH-S macrophages. MH-S macrophages were exposed to different concentrations of HEBI for 60 min and then stimulated with UPM $(31.3 \mu \mathrm{g} / \mathrm{mL})$ for $30 \mathrm{~min}$. The cytosolic phosphorylation levels of cytosolic IkB- $\alpha$ (a,b), p50 (c), and p65 were analyzed by Western blots and quantified using ImageJ software (d). The translocation levels of cytosolic p50 and p65 in the nucleus were analyzed by Western blots (e) and quantified using the ImageJ image processing program (f). Nucleus p50 and p65 levels were normalized against the corresponding Nucleolin. Data are expressed as mean \pm S.D. $(n=3)$. ${ }^{*} p<0.05$ or $^{* *} p<0.01$ compared with the UPM-stimulated group and ${ }^{\# \#} p<0.01$ compared to control group. 


\subsection{HEBI Inhibits MAPK Phosphorylation in UPM-Exposed MH-S Cells}

MAPKs are an evolutionarily preserved family of enzymes capable of forming an integrated network required to complete important cell functions such as apoptosis, cell differentiation, and cell proliferation [11]. ERK1/2, JNK, and p38 are three known MAPKs involved in inflammatory gene regulation; therefore, the compounds capable of inhibiting or down-regulating MAPK-related proteins might have the potential to develop as antiinflammatory drugs; thus, we attempted to evaluate phosphorylation levels of MAPKs in UPM-exposed MH-S cells and HEBI co-treated MH-S cells together with UPM. According to the results, phosphorylated forms of JNK-1 and ERK1/2 were dramatically increased in UPM-exposed MH-S cells (Figure 7a). At the same time, the co-treatment of HEBI decreased the phosphorylation levels of JNK-1 and ERK1/2 in a dose-dependent manner (Figure $7 \mathrm{~b}$ ).

a

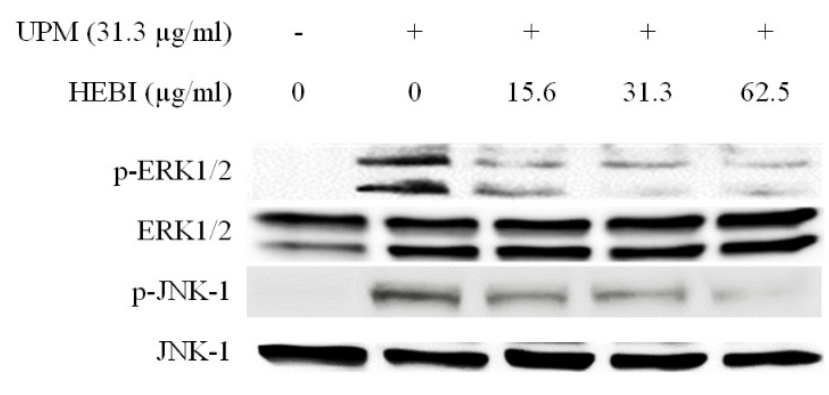

$\mathrm{b}$

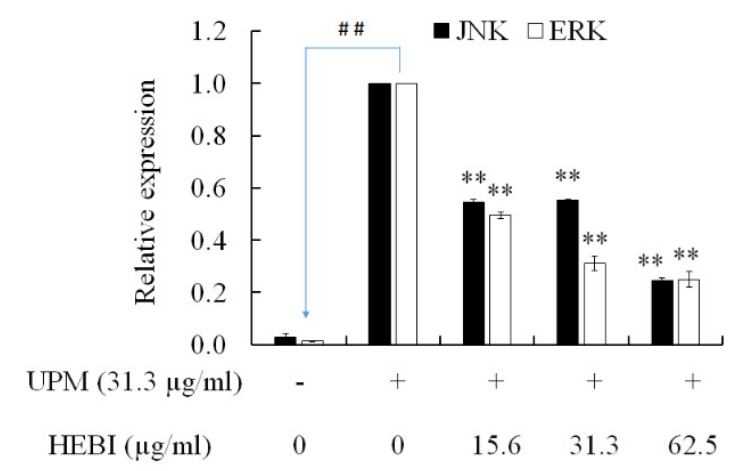

Figure 7. Effect of 3-hydroxy-5,6-epoxy- $\beta$-ionone (HEBI) against urban fine dust (UPM)-activated ERK $1 / 2$ and JNK-1 phosphorylation in MH-S macrophages. MH-S macrophages were pre-treated with different concentrations of HEBI for $60 \mathrm{~min}$ and then stimulated with UPM $(31.3 \mu \mathrm{g} / \mathrm{mL})$ for $30 \mathrm{~min}$. The phosphorylation levels of JNK-1 and ERK1/2 were analyzed by Western blots (a) and quantified using the ImageJ image processing program (b). Data are expressed as mean \pm S.D. $(n=3)$. ${ }^{* *} p<0.01$ compared with UPM-stimulated group and ${ }^{\# \#} p<0.01$ compared to control group.

\section{Discussion}

Marine organisms represent an excellent source of novel bioactive compounds that have the potential for the development of functional materials such as functional foods and nutraceuticals [27]. Among these marine organisms with bioactive compounds seaweeds have been identified as one of the richest sources of bioactive compounds [28]. Recently, several studies demonstrated the potential of seaweed-derived compounds to develop as functional materials due to their strong bioactive properties such as antioxidants, antiinflammatory, anticancer, and antimicrobial properties [27-29]. Similar to previous studies, the results presented in this study demonstrate that HEBI isolated from invasive brown seaweed S. horneri can down-regulate UPM-induced inflammatory responses in MH-S macrophages, which can therefore potentially be a source of commercial ingredient in functional materials. A considerable percentage of the human populations around the globe have long-term exposure to environments with various air pollutants (UPM, $\mathrm{O}_{3}$, $\mathrm{CO}_{2}$, and $\mathrm{NO}_{2}$ ) that can have serious impacts on the balance of natural systems as well as human health $[2,5,30]$. With industrial development, construction works, and natural phenomena, UPM levels in the Korean atmosphere increased dramatically within the last few decades [31]. Specifically, inflammatory diseases in the respiratory system caused by UPM have become a hot topic due to the increased number of cases diagnosed with respiratory symptoms. Specifically, alerted levels of UPM in South Korea, Japan, and China were also found to increase the number of hospital visits due to respiratory diseases [30]. Studies have been confirmed that airborne UPMs $(<2.5 \mu \mathrm{m})$ are the most vulnerable size to induce adverse health effects [25]. Specifically, He et al. (2016) observed elevated levels of inflammatory symptoms in murine lungs after exposing them to UPM 2.5 [6]. 
According to the electron microscope analysis, the UPM tested in the present study showed a considerable amount of UPMs have less than $2.5 \mu \mathrm{m}$ diameter PM. Moreover, particles smaller than $2.5 \mu \mathrm{m}$ can easily reach the alveolus through the throat and nose. Collectively, these results suggest that UPM is a risk factor for respiratory health.

According to the bio-assays guided purifications, one of the active compounds in $S$. horneri is HEBI, which has anti-inflammatory properties. Isolation and purification procedures of HEBI were reported by Kim et al. (2021). Previously, Kim et al. (2018) reported HEBI isolated from $S$. muticum has the potential to reduce LPS-induced inflammatory responses in RAW 264.7 macrophages and zebrafish models via blocking MAPKs and NF- $\kappa B$ signaling pathways. Other than that, Huang et al. (2003) reported, continuous exposure to PM is linked with the pathogenesis of adverse health effects. Specifically, we reported, PM-exposed individuals were diagnosed with pulmonary neutrophilic inflammation and increased blood fibrinogen [32]. On the other hand, several studies suggested that compounds isolated from brown seaweeds are capable to inhibit UPM-induced inflammatory responses under in vivo and in vitro conditions [33,34]. Specifically, Wang et al. (2021) demonstrated the potential of Diphlorethohydroxycarmalol isolated from Ishige okamurae to inhibit PM-Induced skin damage by regulating NF- $\mathrm{B}, \mathrm{AP}-1$, and MAPKs signaling pathways in vitro in human dermal fibroblasts. Taken together, in the present study, we have attempted to evaluate the protective effects of HEBI against UPM-activated inflammatory responses in MH-S macrophages.

Elevated NO secretion is a typical inflammatory response of macrophages during inflammatory events [35]. Several studies reported that exposure of macrophages to UPM resulted in up-regulated production of $\mathrm{PGE}_{2}$ and pro-inflammatory cytokines [26]. The production of $\mathrm{NO}$ and $\mathrm{PGE}_{2}$ mainly depend on the expression levels of iNOS and COX2 proteins, respectively. The production of $\mathrm{NO}$ in the cellular environment depends on the conversion of 1-arginine to l-citrulline by the nitric oxide synthase (NOS). To date, three isoforms of NOS were identified and called iNOS, neuronal NO synthase (nNOS), and endothelial NO synthase (eNOS). In general, the activation of nNOS and eNOS are responsible for producing nano-molar concentrations of $\mathrm{NO}$ for short periods (seconds or minutes); however, the activation of iNOS caused the secretion of large amounts of NO ( $\mu \mathrm{M}$ range) for relatively long periods (from hours to days) [36]. Besides the iNOS; COX2 is the product of an "immediate-early" gene that is rapidly inducible and tightly regulated in cellular environments [37]. Moreover, COX2 is the inducible form of cyclo-oxygenase and plays an important role in inflammation by stimulating the conversion of arachidonic acid to prostaglandins. In normal situations, COX2 cannot secrete from the cells, and expression is avoided. During the inflammatory responses, macrophages secrete a large amount of COX2 to up-regulate inflammatory responses $[37,38]$; therefore, we compared the transcription levels of $i N O S$ and COX2 as well as the protein expression levels of iNOS and COX2 with or without UPM stimulation. As expected, UPM up-regulates the gene transcriptions and protein expression levels of COX2 and iNOS; however, HEBI reduced elevated levels of COX2 and iNOS observed in UPM-exposed cells.

After identifying basic anti-inflammatory properties, we attempted to evaluate possible anti-inflammatory signal pathways of HEBI against UPM-exposed macrophages. The principal role of toll-like receptors (TLRs) is reorganizing specific molecular patterns identical to microbial components. The activation of TLRs controls the distinct patterns of gene expressions linked with the protective mechanisms. TLRs are involved in stimulating innate immunity and the development of antigen-specific acquired immunity [39]. According to the previous observations, up-regulated expression of TNF- $\alpha$ triggers NF- $\mathrm{B}$ and MAPK protein transcription via activating TLR dependent inflammatory pathways [40]. Moreover, TNF- $\alpha$ strongly stimulates the activation of NF- $\mathrm{B}$, and MAPKs stimulate the TNF- $\alpha$ secretion from cells. This positive feedback is key to the pathogenesis of inflammatory complications, including asthma, rheumatoid arthritis, cancer, and inflammatory bowel disease [40]. Interestingly, many studies demonstrated the potential of UPM to induce transcription of pro-inflammatory cytokines such as TNF- $\alpha$, IL-1 $\beta$, and IL-6 from 
macrophages [41]. Additionally, Akira and Takeda (2004) reported that the activation of TLR 2 and 4 was responsible for the production of inflammatory cytokines involved in MyD88-dependent NF- $\mathrm{kB}$ pathway activation. Upon the activation of TLRs, TLR/MyD88 complex dislocate, resulting in downstream activation of the transcription factors related to NF- $\mathrm{KB}$ and MAPKs, which are the primary contributors to pro-inflammatory gene expression [42]; therefore, the up-regulated inflammatory responses observed in MH-S lung macrophages after UPM exposure should be related to the TLRs mediated NF- $\mathrm{KB}$ and MAPK protein expressions. Taken together, with the observations of the present study, it is clear that HEBI has the potential to inhibit UPM-induced inflammatory responses in mouse MH-S lung macrophage cells via down-regulating TLR mediated NF- $\mathrm{KB}$ and MAPK activation. Even though we demonstrated the anti-inflammatory mechanisms of HEBI and its potential to develop as a function material, further studies are warranted to confirm its toxicity and anti-inflammatory mechanisms under in vivo conditions.

\section{Conclusions}

This study explored the anti-inflammatory properties of HEBI-a pure compound isolated from S. horneri using UPM-exposed MH-S macrophages. According to the results, UPM-exposed MH-S cells showed typical inflammatory responses. The RT-qPCR data show that the exposure of UPM activates TLR 2 and TLR 4 in MH-S cells. The activation of TLRs is one possible method of activating inducible genes such as iNOS and COX2 through NF- $\mathrm{kB}$ and MAPKs protein inhibition. Taken together, HEBI has the potential to develop as functional materials to avoid chronic inflammation in the human body due to the proven anti-inflammatory properties against UPM-induced inflammation in MH-S lung macrophages; therefore, the development of functional material from HEBI will be a useful approach to reduce UPM induced inflammatory diseases.

Author Contributions: Conceptualization, K.K.A.S., D.U., J.-I.K. and Y.-J.J.; data curation, K.K.A.S., H.-G.L. and T.U.J.; formal analysis, K.K.A.S.; funding acquisition, K.K.A.S. and Y.-J.J.; investigation, K.K.A.S., H.-S.K., T.U.J. and D.P.N.; methodology, K.K.A.S., H.-S.K., T.U.J., D.P.N. and Y.-J.J.; project administration, H.-W.Y. and Y.-J.J.; resources, J.-I.K. and Y.-J.J.; software, K.K.A.S.; visualization, T.U.J. and D.P.N.; writing—original draft, K.K.A.S.; writing—review and editing, K.K.A.S., D.U. and Y.-J.J. All authors have read and agreed to the published version of the manuscript.

Funding: This research was funded by the Basic Science Research Program through the National Research Foundation of Korea (NRF), funded by the Ministry of Education (2019R1A6A1A03033553).

Institutional Review Board Statement: Not applicable.

Data Availability Statement: The data presented in this study are available on request from the corresponding author.

Conflicts of Interest: The authors declare no conflict of interest.

\section{References}

1. Perini, K.; Ottelé, M.; Giulini, S.; Magliocco, A.; Roccotiello, E. Quantification of fine dust deposition on different plant species in a vertical greening system. Ecol. Eng. 2017, 100, 268-276. [CrossRef]

2. Soberanes, S.; Misharin, A.V.; Jairaman, A.; Morales-Nebreda, L.; McQuattie-Pimentel, A.C.; Cho, T.; Hamanaka, R.B.; Meliton, A.Y.; Reyfman, P.A.; Walter, J.M.; et al. Metformin Targets Mitochondrial Electron Transport to Reduce Air-PollutionInduced Thrombosis. Cell Metab. 2019, 29, 335-347.e335. [CrossRef]

3. Lee, Y.G.; Ho, C.-H.; Kim, J.-H.; Kim, J. Quiescence of Asian dust events in South Korea and Japan during 2012 spring: Dust outbreaks and transports. Atmos. Environ. 2015, 114, 92-101. [CrossRef]

4. Oh, H.-R.; Ho, C.-H.; Koo, Y.-S.; Baek, K.-G.; Yun, H.-Y.; Hur, S.-K.; Choi, D.-R.; Jhun, J.-G.; Shim, J.-S. Impact of Chinese air pollutants on a record-breaking PMs episode in the Republic of Korea for 11-15 January 2019. Atmos. Environ. 2020, $223,117262$. [CrossRef]

5. Jung, S.; Kang, H.; Sung, S.; Hong, T. Health risk assessment for occupants as a decision-making tool to quantify the environmental effects of particulate matter in construction projects. Build. Environ. 2019, 161, 106267. [CrossRef]

6. He, M.; Ichinose, T.; Kobayashi, M.; Arashidani, K.; Yoshida, S.; Nishikawa, M.; Takano, H.; Sun, G.; Shibamoto, T. Differences in allergic inflammatory responses between urban PM2.5 and fine particle derived from desert-dust in murine lungs. Toxicol Appl. Pharmacol. 2016, 297, 41-55. [CrossRef] [PubMed] 
7. Su, R.; Jin, X.; Zhang, W.; Li, Z.; Liu, X.; Ren, J. Particulate matter exposure induces the autophagy of macrophages via oxidative stress-mediated PI3K/AKT/mTOR pathway. Chemosphere 2017, 167, 444-453. [CrossRef] [PubMed]

8. Baldwin, A.S., Jr. The NF-kappa B and I kappa B proteins: New discoveries and insights. Annu. Rev. Immunol. 1996, 14, 649-683. [CrossRef]

9. Tak, P.P.; Firestein, G.S. NF-kappaB: A key role in inflammatory diseases. J. Clin. Investig. 2001, 107, 7-11. [CrossRef]

10. Baeuerle, P.A.; Baltimore, D. NF-kB: Ten Years After. Cell 1996, 87, 13-20. [CrossRef]

11. Hommes, D.W.; Peppelenbosch, M.P.; van Deventer, S.J. Mitogen activated protein (MAP) kinase signal transduction pathways and novel anti-inflammatory targets. Gut 2003, 52, 144-151. [CrossRef] [PubMed]

12. Kaminska, B. MAPK signalling pathways as molecular targets for anti-inflammatory therapy-from molecular mechanisms to therapeutic benefits. Biochim. Biophys. Acta 2005, 1754, 253-262. [CrossRef] [PubMed]

13. Kyriakis, J.M.; Avruch, J. Mammalian mitogen-activated protein kinase signal transduction pathways activated by stress and inflammation. Physiol. Rev. 2001, 81, 807-869. [CrossRef] [PubMed]

14. Kim, H.-S.; Sanjeewa, K.K.A.; Fernando, I.P.S.; Ryu, B.; Yang, H.-W.; Ahn, G.; Kang, M.C.; Heo, S.-J.; Je, J.-G.; Jeon, Y.-J. A comparative study of Sargassum horneri Korea and China strains collected along the coast of Jeju Island South Korea: Its components and bioactive properties. Algae 2018, 33, 341-349. [CrossRef]

15. Choi, H.G.; Lee, K.H.; Yoo, H.I.; Kang, P.J.; Kim, Y.S.; Nam, K.W. Physiological differences in the growth of Sargassum horneri between the germling and adult stages. In Nineteenth International Seaweed Symposium; Borowitzka, M.A., Critchley, A.T., Kraan, S., Peters, A., Sjøtun, K., Notoya, M., Eds.; Springer: Dordrecht, The Netherlands, 2009; pp. 279-285.

16. Sanjeewa, K.K.; Fernando, I.P.; Kim, E.A.; Ahn, G.; Jee, Y.; Jeon, Y.J. Anti-inflammatory activity of a sulfated polysaccharide isolated from an enzymatic digest of brown seaweed Sargassum horneri in RAW 264.7 cells. Nutr. Res. Pract. 2017, 11, 3-10. [CrossRef]

17. Herath, K.H.I.N.M.; Kim, H.J.; Mihindukulasooriya, S.P.; Kim, A.; Kim, H.J.; Jeon, Y.-J.; Jee, Y. Sargassum horneri extract containing mojabanchromanol attenuates the particulate matter exacerbated allergic asthma through reduction of Th2 and Th17 response in mice. Environ. Pollut. 2020. [CrossRef]

18. Byeon, S.Y.; Oh, H.J.; Kim, S.; Yun, S.H.; Kang, J.H.; Park, S.R.; Lee, H.J. The origin and population genetic structure of the 'golden tide' seaweeds, Sargassum horneri, in Korean waters. Sci. Rep. 2019, 9, 7757. [CrossRef]

19. Marks, L.M.; Reed, D.C.; Holbrook, S.J. Niche Complementarity and Resistance to Grazing Promote the Invasion Success of Sargassum horneri in North America. Diversity 2020, 12, 54. [CrossRef]

20. Sanjeewa, K.K.A.; Jayawardena, T.U.; Kim, S.Y.; Lee, H.G.; Je, J.G.; Jee, Y.; Jeon, Y.J. Sargassum horneri (Turner) inhibit urban particulate matter-induced inflammation in MH-S lung macrophages via blocking TLRs mediated NF-kappaB and MAPK activation. J. Ethnopharmacol. 2020, 249, 112363. [CrossRef]

21. Sanjeewa, K.K.A.; Jayawardena, T.U.; Lee, H.G.; Herath, K.; Jee, Y.; Jeon, Y.J. The protective effect of Sargassum horneri against particulate matter-induced inflammation in lung tissues of an in vivo mouse asthma model. Food Funct. 2019, 10, 7995-8004 [CrossRef]

22. Kim, H.-S.; Fernando, I.P.S.; Lee, S.-H.; Ko, S.-C.; Kang, M.C.; Ahn, G.; Je, J.-G.; Sanjeewa, K.K.A.; Rho, J.-R.; Shin, H.J.; et al. Isolation and characterization of anti-inflammatory compounds from Sargassum horneri via high-performance centrifugal partition chromatography and high-performance liquid chromatography. Algal Res. 2021, 54, 102209. [CrossRef]

23. Leiro, J.; Alvarez, E.; Garcia, D.; Orallo, F. Resveratrol modulates rat macrophage functions. Int. Immunopharmacol. 2002, 2, 767-774. [CrossRef]

24. Livak, K.J.; Schmittgen, T.D. Analysis of relative gene expression data using real-time quantitative PCR and the 2(-Delta Delta C(T)) Method. Methods 2001, 25, 402-408. [CrossRef] [PubMed]

25. Bekki, K.; Ito, T.; Yoshida, Y.; He, C.; Arashidani, K.; He, M.; Sun, G.; Zeng, Y.; Sone, H.; Kunugita, N.; et al. PM2.5 collected in China causes inflammatory and oxidative stress responses in macrophages through the multiple pathways. Environ. Toxicol. Pharmacol. 2016, 45, 362-369. [CrossRef] [PubMed]

26. Tsai, M.H.; Hsu, L.F.; Lee, C.W.; Chiang, Y.C.; Lee, M.H.; How, J.M.; Wu, C.M.; Huang, C.L.; Lee, I.T. Resveratrol inhibits urban particulate matter-induced COX-2/PGE2 release in human fibroblast-like synoviocytes via the inhibition of activation of NADPH oxidase/ROS/NF-kappaB. Int. J. Biochem. Cell Biol. 2017, 88, 113-123. [CrossRef]

27. Shikov, A.N.; Flisyuk, E.V.; Obluchinskaya, E.D.; Pozharitskaya, O.N. Pharmacokinetics of Marine-Derived Drugs. Mar. Drugs 2020, 18, 557. [CrossRef]

28. Pozharitskaya, O.N.; Obluchinskaya, E.D.; Shikov, A.N. Mechanisms of Bioactivities of Fucoidan from the Brown Seaweed Fucus vesiculosus L. of the Barents Sea. Mar. Drugs 2020, 18, 275. [CrossRef]

29. Ayrapetyan, O.N.; Obluchinskaya, E.D.; Zhurishkina, E.V.; Skorik, Y.A.; Lebedev, D.V.; Kulminskaya, A.A.; Lapina, I.M. Antibacterial Properties of Fucoidans from the Brown Algae Fucus vesiculosus L. of the Barents Sea. Biology 2021, $10,67$. [CrossRef]

30. Pardo, M.; Xu, F.; Qiu, X.; Zhu, T.; Rudich, Y. Seasonal variations in fine particle composition from Beijing prompt oxidative stress response in mouse lung and liver. Sci. Total Environ. 2018, 626, 147-155. [CrossRef]

31. Kim, P.W. Operating an environmentally sustainable city using fine dust level big data measured at individual elementary schools. Sustain. Cities Soc. 2018, 37, 1-6. [CrossRef] 
32. Huang, Y.C.; Ghio, A.J.; Stonehuerner, J.; McGee, J.; Carter, J.D.; Grambow, S.C.; Devlin, R.B. The role of soluble components in ambient fine particles-induced changes in human lungs and blood. Inhal. Toxicol. 2003, 15, 327-342. [CrossRef] [PubMed]

33. Tan, P.X.; Thiyagarasaiyar, K.; Tan, C.Y.; Jeon, Y.J.; Nadzir, M.S.M.; Wu, Y.J.; Low, L.E.; Atanasov, A.G.; Ming, L.C.; Liew, K.B.; et al. Algae-Derived Anti-Inflammatory Compounds against Particulate Matters-Induced Respiratory Diseases: A Systematic Review. Mar. Drugs 2021, 19, 317. [CrossRef] [PubMed]

34. Wang, L.; Kim, H.S.; Je, J.-G.; Oh, J.Y.; Kim, Y.-S.; Cha, S.-H.; Jeon, Y.-J. Protective Effect of Diphlorethohydroxycarmalol Isolated from Ishige okamurae Against Particulate Matter-Induced Skin Damage by Regulation of NF-kB, AP-1, and MAPKs Signaling Pathways In Vitro in Human Dermal Fibroblasts. Molecules 2020, 25, 1055. [CrossRef] [PubMed]

35. Sanjeewa, K.K.A.; Jayawardena, T.U.; Kim, H.-S.; Kim, S.-Y.; Ahn, G.; Kim, H.-J.; Fu, X.; Jee, Y.; Jeon, Y.-J. Ethanol extract separated from Sargassum horneri (Turner) abate LPS-induced inflammation in RAW 264.7 macrophages. Fish. Aquat. Sci. 2019, 22, 6. [CrossRef]

36. Vannini, F.; Kashfi, K.; Nath, N. The dual role of iNOS in cancer. Redox Biol. 2015, 6, 334-343. [CrossRef]

37. Crofford, L.J. COX-1 and COX-2 tissue expression: Implications and predictions. J. Rheumatol. Suppl. 1997, 49, 15-19. [PubMed]

38. Sutcliffe, S.; Pontari, M.A. Inflammation and Infection in the Etiology of Prostate Cancer. In Prostate Cancer; Mydlo, J.H., Godec, C.J., Eds.; Academic Press: San Diego, CA, USA, 2016; pp. 13-20.

39. Zakeri, A.; Yazdi, F.G. Toll-like receptor-mediated involvement of innate immune cells in asthma disease. Biochim. Biophys. Acta Gen. Subj. 2017, 1861, 3270-3277. [CrossRef]

40. Arango Duque, G.; Descoteaux, A. Macrophage cytokines: Involvement in immunity and infectious diseases. Front. Immunol. 2014, 5, 491. [CrossRef]

41. Seok, J.K.; Lee, J.W.; Kim, Y.M.; Boo, Y.C. Punicalagin and (-)-Epigallocatechin-3-Gallate Rescue Cell Viability and Attenuate Inflammatory Responses of Human Epidermal Keratinocytes Exposed to Airborne Particulate Matter PM10. Skin Pharmacol. Physiol. 2018, 31, 134-143. [CrossRef]

42. Mitchell, J.; Kim, S.J.; Seelmann, A.; Veit, B.; Shepard, B.; Im, E.; Rhee, S.H. Src family kinase tyrosine phosphorylates Toll-like receptor 4 to dissociate MyD88 and Mal/Tirap, suppressing LPS-induced inflammatory responses. Biochem. Pharmacol. 2018, 147, 119-127. [CrossRef] 